\title{
Editorial
}

\section{Attitude model for management}

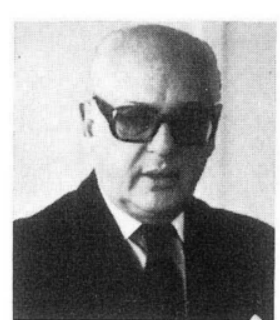

Robert K. Mueller, Chairman of the Board of Arthur D. Little, Inc., is also Director of Arthur D. Little Limited (London). Prior to joining Arthur D. Little in 1968, he was Vice President of Monsanto Company, a member of its Board of Directors and Executive Committee. He is a member of the Board of Directors and Executive Committee of Massachusetts Mutual Life Insurance Company, member of the Board and Executive Committee of Bay Banks, Inc., and member of the Board of MassMutual Income Investors, Inc. He is Vice Chancellor of the International Academy of Management (CIOS); a Fellow of the Institute of Directors (London); Fellow of the American Association for the Advancement of Science; Life member of the American Management Associations; member of the AMA International Council; The New York Academy of Sciences and a Trustee of The Cheswick Center (Boston). He is the author of ten books on management and board of director matters as well as numerous articles in scientific and business journals. In 1970 Mr. Mueller served as Chairman of the Faculty for a Management of Technology session at the Salzburg Seminars in American Studies, and currently he is a member of that organization's Board of Directors and Executive Committee. Mr. Mueller is a Vice Chairman of Trustees of Colby-Sawyer College, New Hampshire. He was appointed Visiting Professor at Manhattan College, Bronx, New York for 1976.

Author's note: This editorial is derived from the author's book, The Incompleat Board: The Unfolding of Corporate Governance, D.C. Heath \& Co., Lexington Books, Lexington, MA, 1981. Excerpted with permission from the Publisher.

North-Holland Publishing Company

Human Systems Management 2 (1981) 135-137
Dryden's phrase “... without ambages or ambiguities" describes the conventional approach to the management of human systems. Management science's main focus has been on productivity, efficiency, logistics and technical competence through innovation. This does not couple naturally with the artistic, intuitive and qualitative approaches to social and political issues which managers must face. The linking of human beings into purposeful teams and the catalyzing of their full creative potential through leadership comes about-if at all-through entangled hierarchies of relationships, strange loops of interdependence and interactions. These reach out in various ways into the realm of management of human systems.

The purpose of Human Systems Management (HSM), namely, promoting a synthesis of these two complementary aspects of managing, is a bold endeavor. Moreover, this proposed paradigm is a somewhat threatening and uncomfortable construct for members of the executive suite and the boardroom to accept and to internalize. A new attitude model for management is needed.

\section{Dimensions of management}

Those in charge of the corporate ship of state are not unlike those determining the positioning of an aircraft. Attitude is determined by the relationship between certain dimensional axes and a reference point such as the horizon or a particular star. In the case of corporate management, we have come a long way in recent years toward recognizing these two main dimensions of management. Oversimplified, these dimensions are the science or technology of management and the art of management.

Historically, our managerial reference point has been confined primarily to an economic-based horizon. Each enterprise has its particular 'star'; namely, its mission or economic goal. But social complexity, social pressures and political forces have challenged 
those who would manage our institutions with a single economic star as reference. A single goal is inadequate given the complexity, the uncertainty and the velocity of change in the world today. Multiple goals, multiple criteria and multiple standards are now recognized by more thoughtful managers as a natural condition to be faced. Effective strategies, plans and contingencies recognize this multiplicity and complexity as a fact of corporate existence.

In thinking about an attitude model for management, given such a complex environment, we must delve into our personal domain. Personal beliefs, values, preferences and expectations can have great influence upon managerial attitudes. In the past, with less complexity and a steadier environment, a more or less rational attitude seemed comfortable for management. However, in dealing with the current and future environment, acceptance of the concept of incompleteness, of an open versus a closed system, becomes the challenge for thinking managers.

The two dimensions of management are reflected in this 'new' attitude model for management as follows:

(1) the 'hard' intellectual areas of logic, mathematics, economics and the physical sciences and

(2) the 'soft' intellectual domains of psychology, sociology, theology, humanities, philosophy, art and anthropology.

These latter domains are often emotional and subjective. Managing the relationship between these hard and soft dimensions requires a delicate balance. In a way, it is a balance between unqualified disbelief on the one hand and absolute certainty on the other hand.

\section{The chimera of completeness}

These polarities of mental attitude may relate to the two-sided nature of the brain. They represent the dual processes of thought which characterize a balanced intellectual. These are the rational/logical and the subjective/emotional approaches to perceiving situations, to solving problems, or to making management decisions. The incomplete nature of our knowledge of the latter subjective processes, which we use intuitively in management, should not be cause for distress. To have an elaborately refined process embracing all knowledge would make for a dull existence and certainly for inhuman management. The sheer complexity of the subjective and objective processes involved in thinking, managing and govern- ing requires acceptance of ambiguity. To attempt completeness in pursuit of certainty is inappropriate for the manager. The chimera of completeness and the asset of ambiguity are part of the new horizon for those of us who would manage in these complex and uncertain times.

Dealing with complexity and incompleteness in a credible manner is no small managerial task. The misty domain of management embraces values, ethics, beliefs, prejudices, biases, norms, conventions, proto$\mathrm{col}$ and rituals. These are all nutrients in which a manager must thrive if he/she is to be successful. This stew increasingly tends to overshadow or conflict with the 'harder' elements of economic and environmental corporate circumstances, as the world becomes more interactive and interdependent.

Managing economic tradeoffs, seeking zero-defect production, coping with environmental tolerance standards, and the 'problem of the commons' are examples of value-laden issues on the soft side of management. The complexity of the manager's position can be overwhelming to an individual, but not so much in its formal structure as in its unfathomable, subjective dimension. The pure mathematicians are, of course, acknowledging these gray areas of incompleteness through fuzzy-set methodology. Such methods may become useful in dealing with the hazy, ill-defined situations'which exist on the human side of the management equation. Preservation of the incomplete and open-ended nature of management is necessary if we are to intelligently nurture the true art of human systems management.

\section{The asset of ambiguity}

Good management requires the ability to wallow in ambiguity with aplomb, and without the bias or limitation of a preconceived logical paradigm. In some respects vagueness is a virtue. As the manager makes choices and engages in subtle interactions, he or she must be comfortable with the equivocal nature of their environment. Sociocultural variables such as attitudes, beliefs, value systems and need hierarchies are prime elements of each management situation. They ultimately have a strong impact on management practice and effectiveness. These cultural manifestations are often obscure and subliminal, leading to ambiguity and forcing us to think in terms of multiple influences.

Ambiguity in organizations corresponds to the 
fuzziness of information available to the managers and employees. Role definition, accuracy and speed of feedback are involved. The greater the task uncertainty, the greater the amount of information to be processed. Clarity and role definitions are necessary to mitigate ambiguity, as is accurate, timely feedback of information. For a manager, the problem is first one of understanding his or her role within the organization. Then the problem becomes one of coping with the paucity or surplus of information available for day-to-day decisions and actions. This exercise involves both the art and science of management.

The imprecision of information, its lack of distinct structure, may be due to the subject being either overly general, improperly conceived or thought out, or incapable of clear formulation. This latter type of vagueness, causing a fluidity of managerial boundaries, does not necessarily imply a chaotic, unorganized approach. The complexity of a system may increase to a point where it becomes impractical or infeasible to make precise statements about it. Thus the fact that the managerial system is vague and imprecise is not all bad. Lack of firmness may be important in personal interactions, in dealing with emotional situations and political factors, and in provid- ing flexibility to respond to new phenomena. Thus there is a credible rationale for the deliberate use of ambiguity and vagueness in the managerial process.

Recent research has shown that the benefits of managing ambiguity are apparently worth the costs. Originally, it was believed that the profit-center measurement system was a tool of crucial importance in the management of decentralized firms. However, while measurement systems are indeed important, they were found less important than the primary factors of authority and autonomy. In contrast to the clear lines of functional authority in centralized organizations, decentralization produces contradictory and ambiguous roles for profit-center managers, and does so intentionally.

The suggested attitude model for management accepts ambiguity as an asset to the process of managing. The mystique of managing - like the power and mystery of the mind - will always be enhanced by the asset of ambiguity. Our comfort letter, as directors and managers striving to be effective, may come from Plato's teachings: "Poets utter great and wise sayings which they do not themselves understand ...".

Robert K. MUELLER 